The increasing numbers of family planning clinics in the developing areas of the world provide an ideal setting for a screening programme. This is an important part of the service in my family planning clinics for Black Africans in Johannesburg. All our patients have a medical and gynaecological examination and a Pap smear if indicated. As I am the only doctor supervising four busy clinics most of the responsibility for the screening falls on my nurses. Initially, they performed many bimanual examinations under my supervision and all abnormalities were demonstrated. They were soon able to recognize quite minor deviations from the normal-for example, early pregnancy, adnexial masses, pelvic infection, prolapse, identified other abnormalities such as thyroid disease and breast lumps. Patients with pathological findings are then referred for a medical opinion.

My findings with respect to the use of paramedical personnel in health screening are confirmed by many more experienced authors-for example, by Ostergard et al. ${ }^{1}$ in the U.S.A., where the cost of medical care rather than shortage of doctors is encouraging the use of medical auxiliaries.-I am, etc.,

SUSAN M. HALL

Johannesburg,

1 Ostergard, D. R., Broen, E. M., and Marshall, J. R., Advances in Planned Parenthood, 1972,

\section{Variations in Plasma Urea and Creatinine}

SIR,-Estimation of the blood urea concentration is widely used as a screening test of renal function. Addis ${ }^{1}$ compared the serum concentrations of creatinine and urea in normal men eating diets containing 0.5 $2.5 \mathrm{~g}$ of protein $/ \mathrm{kg}$ body weight and showed that the creatinine concentrations varied less than those of urea.

A comparison has been made between plasma urea and creatinine sampled hourly in a 30-year-old male weighing $70 \mathrm{~kg}$ while on three different protein diets. The subject had normal renal function as judged by and vulval lesions-and they have also

endogenous creatinine clearance and during the experiment he continued working as a medical registrar. The isocaloric diets contained $40 \mathrm{~g}(0.57 \mathrm{~g} / \mathrm{kg}), 70 \mathrm{~g}(1 \mathrm{~g} / \mathrm{kg})$, and $120 \mathrm{~g}(1.7 \mathrm{~g} / \mathrm{kg})$ of protein respectively. An interval of one week elapsed between each day of study. Blood samples were saved and all were estimated in a Technicon-AutoAnalyzer on the same oocasion.

The figure shows that fasting plasma urea levels were very comparable, but after large breakfast ( $26 \mathrm{~g}$ protein) the level increased to the upper limit of normal. Following lunch containing $36 \mathrm{~g}$ of protein urea production exceeded the maximum rate of clearance and the plasma concentration became abnormal. Plasma creatinine concentrations remained essentially constant in the 16 samples taken in each experimental day.

These findings indicate that for accuracy blood urea should be sampled only shortly after breakfast and that specimens taken during afternoon clinics may prove misleading. Measurement of the plasma creatinine level avoids this problem. This work is being extended to include patients of varying ages and to include other biochemical variables. - I am, etc.,

\section{ROGER GABRIEL}

Department of Nephrology, Royal Infirmary,
Hull

1 Addis, T., Glomerular Nephritis. New York, Macmillan, 1948.

\section{Levodopa in Coma Due to Fulminant Hepatitis}

SIR,-So far we have used levodopa together with conventional therapy in 11 cases of hepatic coma due to fulminant hepatitis. The drug dissolved in water is easily administered to a comatose patient through a gastric tube. Three of our 11 patients recovered with this treatment.

Case 1.-This was a 23-year-old woman who had been in grade 4 coma for three days. Routine treatment was ineffectual. Exchange blood transfusion was not attempted. Levodopa $5 \mathrm{~g}$ was given through a gastric tube. After 15-20 minutes the patient moved her hands and after 45-50 minutes

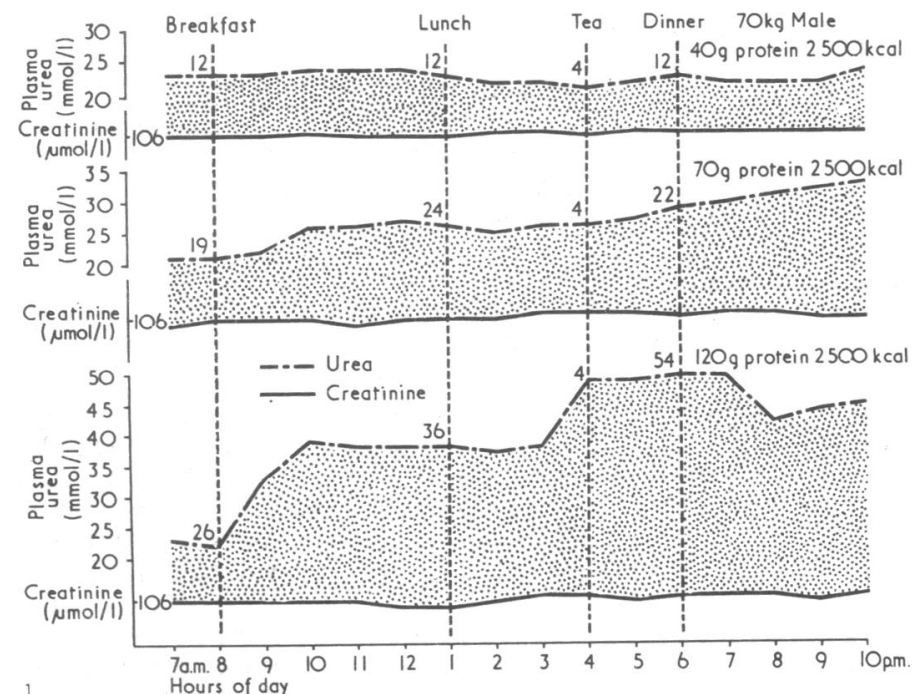

Variations in Plasma Urea and Creatinine Concentrations over 24-hour Periods on Diets of Different Protein Content.

Conversion: SI to Traditional Units. Urea: $1 \mathrm{mmol} / 1 \approx 6 \mathrm{mg} / 100 \mathrm{ml}$. Creatinine $1 \mu \mathrm{mol} / 1 \approx 0.01 \mathrm{mg} / 100 \mathrm{ml}$. she opened her eyes and appeared to be waking. She soon relapsed into coma. A second dose of levodopa was given 12 hours later. After 50-60 minutes the patient opened her eyes and started to talk, though still slightly confused. By the end of the day she regained full consciousness.

Case 2.-This was a 30-year-old woman who had been in coma for three days. She did not had been in coma for three days. She did not there to levodo $6 \mathrm{~g}$, bu there was rapid improvement 30 minutes after an whe was able to talk and obey commands. She regained full consciousness some 48 hours after the first dose of evodopa.

Case 3.- This was a 19-year-old man in his third day of coma. He was given $6 \mathrm{~g}$ of levodopa with no success but a second dose 18 hours later produced a rapid and spectacular response. The patient opened his eyes, moved his hands, and answered opened his eyes, moved his hands, and answered
questions. A few hours after that he regained full questions. A few hours after that he re

The other eight patients treated with levodopa The other eight patients treated with
showed no improvement and they died.

The mechanism of the metabolic disturbances leading to coma in cases of acute hepatic failure is not known with certainty. A disorder of neurotransmission at the neural synapses of the reticular formation has been incriminated, and perhaps levodopa acts as a neurotransmitter. The rapid improvement in the clinical condition in the cases described and the favourable outcome seemed to be due to levodopa.-We are, etc.,

\section{P. A. Contoyiannis}

E. DRAGINIS

D. A. ADAMOPOULOS

G. TRIANTAFyliou

Athens

\section{Endotoxaemia}

SIR,-As your leading article (28 December, p. 730) so succinctly states, whether endotoxin is detectable or not in endotoxic shock depends on the functional capacity of the liver and its degree of perfusion. The limulus material used in 1970 was not as sensitive as that now available. The statement that some patients with Gram-negative shock then had negative assays does not refute the role of endotoxin but serves to emphasize that even now the test has to be refined and that some thought should be given to the tissue used for assay (for example, better results can be obtained from platelets or liver).

Endotoxin is not only a powerful vasoconstrictor but it is difficult, and somewhat academic, to dissociate among the causes of impaired tissue perfusion the associated disseminated intravascular coagulation, the release of lysosomal proteases, the kinin activation, the possible role of complement, and the metabolic effects. Since staphylococcal alpha-toxin has some similar actions; this explains the discrepancy which you appear to use as an argument against a definitive role of $\mathrm{Gram}$-negative endotoxins.

The work of Cuevas et al. ${ }^{1}$ in relation to burns is of interest, but should not be taken out of context to detract from previous work of the same group, and that of others, which suggests that a period of bowel ischaemia induced by poor perfusion in certain species during shock gives rise to portal endotoxinaemia. The crucial question is whether this applies to man.-I am, etc.,

NIGEL WARDLE

St. Peter's Hospital,

Chertsey, Surrey

1 Cuevas, P., et al., Surgery, Gynecology and 